\title{
A Brief History Of Publishing Papers On Astronomy Education Research
}

\author{
Andrew Fraknoi, Foothill College, USA
}

\begin{abstract}
While some research had been done on $K-12$ and planetarium astronomy teaching from the 1930's to the 1980's, the growth of research on college physics education offered astronomy education researchers a model for examining techniques for teaching introductory college astronomy survey "Astronomy 101" courses as well. This early research was published in widely scattered journals and rarely reached the practitioners of astronomy education. The need to inform and unite the community of astronomy educators led to the birth of the journal "Astronomy Education Review," whose history and sudden death is analyzed. This paper provides a short history of publishing astronomy education research results and provides context for the advent of the new "Journal of Astronomy \& Earth Sciences Education" (JAESE).
\end{abstract}

Keywords: Astronomy Education; Astronomy Education Research; Astronomy Education Review; Publishing; History Of Astronomy

\section{EARLY HISTORY}

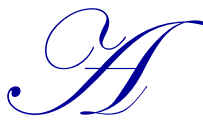

lthough astronomy education papers appeared as early as the 1930's, the modern era of astronomy education research essentially began with projects that probed learning in both the K-12 classroom and the planetarium in the 1960's and 1970's (viz., Wall, 1973 and Bishop, 1977). During the 1980s and 1990s, physicists began using their research training to understand teaching and learning in physics (viz., Beichner, 2009.) This provided a model and pathway for interested astronomers to start studying teaching and learning in the introductory astronomy survey course for college non-science majors, often known as ASTRO 101. Papers describing this early work were mostly published in journals reporting on science education research in general, rather than astronomy specifically. Bishop (2002), Bailey and Slater (2004), Bailey and Slater (2005), and Lelliott and Rollnick (2010), among others, provide extensive overviews of astronomy education work published during this early period.

The problem was that most of the practitioners of astronomy education were trained as scientists and were inclined to read astronomy journals, rather than the science education journals in which this astronomy education research was being published. Furthermore, few of the academic readers of science education journals were engaged in much astronomy teaching. This meant that any ideas or concerns that emerged from the research being done into the efficacy of astronomy teaching techniques rarely reached those astronomy professors who would most have benefited from reading it.

Journals such as The Astrophysical Journal and Astronomical Journal connected research astronomers, while magazines such as. Sky \& Telescope and Astronomy connected serious amateur astronomers. However, there was no publication that tied together astronomy educators into a cohesive community, with common standards, common vocabulary, and a common literature.

For a brief period in the mid-1980's, Astronomy magazine published a one-color supplement called "Astronomy Educator," but it was not a financial success and was soon discontinued. The Astronomical Society of the Pacific publishes a newsletter on teaching astronomy in grades $3-12$, called The Universe in the Classroom, begun in 1984 with the present author as its founding editor, and now available on the web at: 
https://www.astrosociety.org/publications/universe-in-the-classroom/. However, this brief newsletter covers only astronomical subject matter and one classroom activity in each issue, and rarely covers astronomy education research or developments in educational techniques and materials. During the 1990's, The Physics Teacher, published by the American Association of Physics Teachers, featured a monthly column called "AstroNotes," collected in Slater and Zeilik (2003). While the American Journal of Physics and the Journal of Geoscience Education did publish a few articles related to astronomy education research, those publications were largely focused on physics and geoscience education. And, while a number of different educational newsletter and bulletins have been published by various parts of the NASA educational infrastructure over the years, these were purposely devoted mostly to coverage of NASA projects and NASA results. Table 1 provides a non-exhaustive list of astronomy education publications currently in circulation.

Table 1: Other Astronomy Education Publications as of December, 2014

\begin{tabular}{|l|l|l|}
\hline \multicolumn{1}{|c|}{ Name } & \multicolumn{1}{|c|}{ Web Location } & \multicolumn{1}{c|}{ Description } \\
\hline $\begin{array}{l}\text { The Classroom } \\
\text { Astronomer }\end{array}$ & http://www.classroomastronomer.com/ & $\begin{array}{l}\text { Self-published magazine aimed at } \\
\text { high-school teachers; subscriptions } \\
\text { pay for costs }\end{array}$ \\
\hline $\begin{array}{l}\text { Communicating } \\
\text { Astronomy with the } \\
\text { Public (CAP) Journal }\end{array}$ & $\underline{\text { http://www.capjournal.org/ }}$ & $\begin{array}{l}\text { Color magazine/journal published by } \\
\text { International Astronomical Union } \\
\text { Commission 55; free; deals with } \\
\text { astronomy outreach }\end{array}$ \\
\hline $\begin{array}{l}\text { Journal and Review of } \\
\text { Astronomy Education } \\
\text { and Outreach }\end{array}$ & $\underline{\text { http://jraeo.com/ }}$ & $\begin{array}{l}\text { Self-published on-line journal; } \\
\text { subscriptions pay for costs }\end{array}$ \\
\hline $\begin{array}{l}\text { Latin American Journal } \\
\text { of Astronomy Education }\end{array}$ & $\underline{\text { http://www.relea.ufscar.br/ }}$ & $\begin{array}{l}\text { On-line journal from Brazil; free; in } \\
\text { Portuguese, Spanish, or English }\end{array}$ \\
\hline Mercury & $\underline{\text { https://www.astrosociety.org/publications/mercury-magazine/ / }}$ & $\begin{array}{l}\text { Features articles on astronomy } \\
\text { education regularly; only available } \\
\text { with membership in the Astronomical } \\
\text { Society of the Pacific }\end{array}$ \\
\hline SPARK & $\underline{\text { http://aas.org/teach/spark-aas-education-newsletter }}$ & $\begin{array}{l}\text { Informal occasional free newsletter } \\
\text { from the American Astronomical } \\
\text { Society; last issue in 2011 }\end{array}$ \\
\hline
\end{tabular}

\section{THE BIRTH OF ASTRONOMY EDUCATION REVIEW}

For much of the late 1980's, several of us concerned about the issue of where to publish astronomy education research papers and news formed a variety of informal committees and task groups, including one through the American Astronomical Society (AAS). We frequently discussed that, without a place to publish its work, a sub-discipline community has trouble being treated as professional by comparable communities. This was certainly an issue with astronomy education researchers who were trying to bridge the sometimes disparate worlds of astronomy and science education (Fraknoi, 2005).

Furthermore, the lack of a commonly shared repository of established knowledge - both in terms of astronomy education research and accepted astronomy teaching practice made it hard for newly entering practitioners in astronomy education to get up to speed on what had already been done. Everyone was quick to agree that a journal and a newsletter could do the astronomy education community quite a bit of good. Where the discussions always foundered was the question of where the financial support for such enterprises might come from.

In 1999, the present author (AF) was the chair of the AAS task force on the need for an astronomy education research journal/magazine, but we were no closer to finding a way to publish one. Then, through a conversation with Sidney Wolff (SW), then the Director of the National Optical Astronomy Observatories (NOAO), a solution presented itself. SW was retiring as the observatory director and looking for a new project. At the same time, the rapid expansion of the Internet made it possible to publish and distribute a new journal completely electronically, and at a relatively low cost. SW said that if AF could write a detailed white paper and web outline of the journal's goals, sections, and requirements, she may be able to leverage the NOAO infra-structure to program and publish the much needed, peer-reviewed journal. 
From those informal discussions, Astronomy Education Review (AER) was born. We published the first issue on line starting in October 2001, leaving the issue open until a sufficient number of articles accumulated to close it, in January 2002. We spelled out our aims in publishing the journal in an editorial in that first issue (Fraknoi $\&$ Wolff, 2002). We hoped to begin a publication that included more than just technical research papers. As in Nature and Science, we imagined that the research papers would be supplemented by editorials, news items, discussions of issues, resource reviews, and other items of interest to practicing educators. Neither the authors nor the readers paid any fee for online access to AER. The costs involved in infrastructure, editing, and publishing electronically were generously born by NOAO.

The journal was published continuously for 12 volumes, ending in December 2013. When SW retired from NOAO, the Observatories asked to be released from its commitment to provide infrastructure for the journal, and the AAS graciously agree to take the journal over and, for the time being, continue to subsidize its costs.

As a result, in 2009, the infrastructure for the journal was competitively awarded to the American Institute of Physics, which already had a significant number of electronic journals in its stable. The advantages and new procedures involved were described and documented elsewhere by Fraknoi and Wolff (2009). The AAS also hired a new editor, Thomas Hockey of the University of Northern Iowa, who had edited books and publications on the history of astronomy for many years.

\section{THE DEATH OF ASTRONOMY EDUCATION REVIEW}

Under the AAS and a new editor, AER became more like The Astronomical Journal, in that it included, for the most part, only papers in astronomy education research, and little of the other material that we had originally envisioned would be of interest to educators and would serve to attract readers who were not themselves researchers. After all, the community of astronomy education researchers is still quite small, while the community of astronomy educators is much larger. Also, unfortunately, some of the efforts that had been made at the beginning to publicize $A E R$ regularly and actively to solicit new contributions for its pages were also discontinued.

By 2013, the number of published papers in AER had slowed considerably and some observers felt that the contents of the journal were not as leading-edge in its field as the papers in other AAS journals were in theirs. That year, two reviews of $A E R$ were conducted, one by the AAS Education Board and the other by the AAS Publications Board. While the former review strongly urged the Society to make changes to improve the journal, the latter recommended discontinuing it. After debate the AAS Council went with the recommendation of the Publications Board and ended support for the journal's decade long publication as of the end of 2013, committing only to fund keeping its archives available perpetually at http://aer.aas.org.

\section{NEXT STEPS}

In the fall of 2013, the AAS Council and Executive Office put the word out to see if another organization or group wanted to take over AER or create another journal like it. Several organizations, including the Astronomical Society of the Pacific and the American Association of Physics Teachers, held discussions about what to do next, but these did not lead to any concrete steps toward a new journal so far. Now, JAESE is one of several recent efforts to see if a new business model may be the answer.

Although the pace of astronomy education research is greater now than it was before AER got started, it still may not be sufficient to support a research journal by itself. This, I suspect, is why JAESE has chosen to expand the coverage to the broader domain of earth science as well as space and planetary sciences. Only time will tell whether they will succeed, but many of us involved with $A E R$ and astronomy education wish them well as they begin. 


\section{AUTHOR INFORMATION}

Andrew Fraknoi is the Chair of the Astronomy Department at Foothill College and was the California Professor of the Year in 2007. He served as the Executive Director of the Astronomical Society of the Pacific from 1978 to 1992, and was the founding co-editor of "Astronomy Education Review." E-mail: fraknoiandrew@ fhda.edu

\section{REFERENCES}

Bailey, J. M., \& Slater, T. F. (2003). A review of astronomy education research. Astronomy Education Review, 2(2), 20-45. http://dx.doi.org/10.3847/AER2003015

Bailey, J. M., \& Slater, T. F. (2005). Resource letter AER-1: Astronomy education research. American Journal of Physics, 73(8), 677-685.

Bishop, J. E. (1977). United States astronomy education: Past, present, and future. Science Education, 61(3), 295-305.

Bishop, J. E. (2002). Pre-college Astronomy Education in the United States in the Twentieth Century. In Information Handling in Astronomy-Historical Vistas (pp. 207-231). Springer Netherlands.

Beichner, R. J. (2009). An introduction to physics education research. Getting Started in PER. Available online at: http://physics2.sciencecommunity.wikispaces.net/file/view/Introduction to PER.pdf

Fraknoi, A. (2005). Steps and missteps toward an emerging profession. Mercury, 34(5), 19-25. Online at: http://www.astrosociety.org/pubs/mercury/34_05/epo.pdf

Fraknoi, A., \& Wolff, S. (2001). Welcome to Astronomy Education Review. Astronomy Education Review, 1(1), 117-120. http://dx.doi.org/10.3847/AER2001010

Fraknoi, A., \& Wolff, S. (2009). Astronomy Education Review Version 2.0: A Welcome and Guide" Astronomy Education Review, 8(1), 1. http://dx.doi.org/10.3847/AER2009017

Lelliott, A., \& Rollnick, M. (2010). Big ideas: A review of astronomy education research 1974-2008. International Journal of Science Education, 32(13), 1771-1799.

Slater, T. F., \& Zeilik, M. (Eds.). (2003). Insights Into the Universe: Effective Ways to Teach Astronomy. American Association of Physics Teachers.

Wall, C. A. (1973). A review of research related to astronomy education. School Science and Mathematics, 73(8), 653-669. 